\title{
Kiln drying behavior utilizing drying rate of lumber from six fast-growth plantation species in Costa Rica
}

\section{Carolina Tenorio, Cynthia Salas \& Róger Moya}

To cite this article: Carolina Tenorio, Cynthia Salas \& Róger Moya (2016) Kiln drying behavior utilizing drying rate of lumber from six fast-growth plantation species in Costa Rica, Drying Technology, 34:4, 443-453, DOI: 10.1080/07373937.2015.1060493

To link to this article: https://doi.org/10.1080/07373937.2015.1060493 Jun 2015. Published online: 15 Jun 2015.

Submit your article to this journal $₫$

Џ Article views: 68

Q View related articles $\widetilde{ }$

View Crossmark data $\nearrow$

Citing articles: 4 View citing articles $₫$ 


\title{
Kiln drying behavior utilizing drying rate of lumber from six fast-growth plantation species in Costa Rica
}

\author{
Carolina Tenorio, Cynthia Salas, and Róger Moya \\ Instituto Tecnológico de Costa Rica, Escuela de Ingeniería Forestal, Cartago, Costa Rica
}

\begin{abstract}
The objective was to study the effect of the drying time and moisture content variations on the drying rate during kiln drying. The moisture content is a good predictor of the variation in drying rate; to determine the drying rate, the model DR $=a^{*} t+b$ (where DR is the drying rate, $t$ is the drying time, and $a$ and $b$ are constants) was used. Cordia alliodora, Dipterix panamensis, Hieronyma alchorneoides, and Vochysia ferruginea show a unique tendency, whereas Enterololium cyclocarpum and Samanea saman showed two tendencies. Drying rate in relation to time showed that it is possible to define the various stages during drying and the inflexion points in time where a change in the drying rate occurs. Two types of tendencies are shown in the drying rate vs. time relation in C. alliodora, E. cyclocarpum, and S. saman, whereas three tendencies appear in D. panamensis, $H$. alchorneoides, V. ferruginea. C. alliodora, E. cyclocarpum, and S. saman presented only one inflexion in the drying rate, which can be maintained at an average of $24.5,11.64$, and $7.83 \% /$ day, respectively, for those species. On the other hand, D. panamensis, H. alchorneoides, and $V$. ferruginea showed two inflexions.
\end{abstract}

\section{KEYWORDS}

Dry bulb temperature; inflexion; target moisture content; wet bulb temperature

\section{Introduction}

Kiln drying is the most widely employed drying method for systematically removing water from the lumber and for reaching a target moisture content within a reasonable drying time. The majority of kiln dryers work with a specific range of temperature and relative humidity, which depend on the lumber species to be dried and on the quality and final use of the product. ${ }^{[1]}$ Lumber drying is one of the most important stages in the manufacturing processes, because it contributes to dimensional stability, workability, and compatibility of the lumber with finishes and adhesives. Drying also increases the lumber's mechanical properties and resistance to biological degradation and improves its thermal, acoustic, and electrical isolation properties. ${ }^{[2,3]}$

Adequately performing the drying process provides a final product with the appropriate characteristics. It is important to maintain good control of all of the stages of the process with the purpose of preventing the occurrence or increase in defects, ${ }^{[2,4]}$ which not only lead to a reduction in the economic value of the lumber but also to a decrease in its properties. ${ }^{[2]}$ In addition, maintaining control of the various stages of the drying process provides better control of the drying time, which is necessary to achieve a higher economic profit. ${ }^{[5]}$
Drying rate (the loss of moisture within a time lapse) is a variable that can positively influence the quality and duration of the drying. This parameter is affected by characteristics inherent to the lumber, ${ }^{[6,7]}$ the characteristics of the drying chamber, ${ }^{[8]}$ and the environmental conditions in the chamber (temperature, relative humidity, and wind speed) present during drying. ${ }^{[6]}$

Several research works have been conducted on the effect of various factors on the drying rate. For example, Klitzke and Batista ${ }^{[7]}$ used the drying rate as a predictor of the drying quality of three eucalyptus species by analyzing its defects. The effect of water vaporization on the drying rate of wood has also been studied. ${ }^{[9,10]}$ However, few studies ${ }^{[11]}$ have researched the drying rate variations in relation to the drying time or the effect of a moisture content decrease on the drying rate. One of the few studies that reported these effects was conducted by Shahverdi et al., ${ }^{[1]}$ in which the authors studied the effect of the wet bulb depressions on the drying rate of Populus alba lumber.

There are many studies available on the behavior during kiln drying of different tropical timber species from natural forests, ${ }^{[3,12,13]}$ but few involved research on the drying rate. The studies on the drying of lumber that comes from fast-growth forest plantations of native tropical-climate species are even more limited. ${ }^{[14]}$ For example, Moya et al. ${ }^{[14]}$ evaluated, among other

CONTACT Róger Moya rmoya@itcr.ac.cr E Instituto Tecnológico de Costa Rica, Escuela de Ingeniería Forestal, P.0. Box 159-7050, Cartago, Costa Rica. Color versions of one or more of the figures in the article can be found online at www.tandfonline.com/ldrt. 
Table 1. Dosimetric parameters and age of the plantations sampled.

\begin{tabular}{lrcccc}
\hline Species & $\begin{array}{c}\text { Age } \\
\text { (years) }\end{array}$ & $\begin{array}{c}\text { Density } \\
\text { (trees/ha) }\end{array}$ & $\begin{array}{c}\text { Total } \\
\text { height } \\
(\mathrm{m})\end{array}$ & $\begin{array}{c}\text { Diameter } \\
\text { at breast } \\
\text { height }(\mathrm{cm})\end{array}$ & $\begin{array}{c}\text { Heartwood } \\
(\%)\end{array}$ \\
\hline $\begin{array}{l}\text { Cordia alliodora } \\
\text { Dipteryx } \\
\text { panamensis }\end{array}$ & 14 & 439 & 14.6 & 14.0 & 23.4 \\
$\begin{array}{c}\text { Enterolobium } \\
\text { cyclocarpum }\end{array}$ & 13 & 458 & 20.4 & 15.6 & 24.8 \\
$\begin{array}{c}\text { Hieronyma } \\
\text { alchorneoides }\end{array}$ & 20 & 122 & 14.8 & 35.4 & 33.1 \\
$\begin{array}{c}\text { Samanea saman } \\
\text { Vochysia } \\
\text { ferruginea }\end{array}$ & 12 & 332 & 24.8 & 22.8 & 10.3 \\
\hline
\end{tabular}

parameters, the average drying rate of 10 species from fast-growth plantations in Costa Rica, including native and exotic species. This study found that the drying rate varied from 4.8 to $30.5 \%$ /day. Additionally, it was found that half of the tropical plantation species show initial moisture contents $\left(\mathrm{MC}_{i}\right)$ above $110 \%$ and that the average drying rate is positively correlated to the specific gravity of the lumber. However, these studies do not establish the effect of the moisture content variation or the drying time on the drying rate.

On the other hand, species from fast-growth forest plantations in Costa Rica have been studied extensively. ${ }^{[15,16]}$ At present, it is possible to find information regarding the physical, chemical, mechanical, and fuel wood properties $^{[17,18]}$; about the behavior during drying ${ }^{[14,19]}$; as well as preservation and durability and workability of some of the native and exotic species. ${ }^{[20]}$ However, no information regarding the drying processes of native species like C. alliodora, D. panamensis, E. cyclocarpum, H. alchorneoides, S. saman, and V. ferruginea-which have been used in Costa Rica in various reforestation projects $^{[15,20-22]}$-is available, which causes a serious restriction to their use and exploitation.
Knowledge of the effects of drying time and moisture content variations on the drying rate of lumber during the kiln drying process of various fast-growth forest species in tropical climates will help improve control over the various stages of the drying process, and this will be reflected in the quality and costeffectiveness of the drying process of the lumber. Therefore, the purpose of the present study is to determine the drying rate behavior of lumber, in addition to establishing variation models, the drying time inflexions, and the decrease in moisture content of the lumber, based on the drying rate of six species native to Costa Rica (C. alliodora, D. panamensis, E. cyclocarpum, H. alchorneoides, S. saman, and $V$. ferruginea), which are little known in the tropical area.

\section{Materials and methods}

\section{Plantation description and tree sampling}

Six different pure plantations located in several parts of Costa Rica were studied: C. alliodora, D. panamensis, E. cyclocarpum, H. alchorneoides, S. saman, and $V$. ferruginea. The initial planting density was 1,100 trees/ha $(3 \times 3 \mathrm{~m}$ spacing). At the time of sampling, the age varied from 9 to 20 years old and the density was at 122-575 trees/ha (Table 1). A total of nine trees per species were randomly selected for felling, including suppressed, intermediate, and dominant trees, in accordance with the methodology developed by Moya and Muñoz. ${ }^{[17]}$ Selected trees with straight trunks, normal branching, and no disease or pest symptoms were felled. Stem logs $2.5 \mathrm{~m}$ long were cut from the basal part to the commercial height (a stem diameter of $13.0 \mathrm{~cm}$ over the bark is considered as the minimum diameter for these species in Costa Rica).

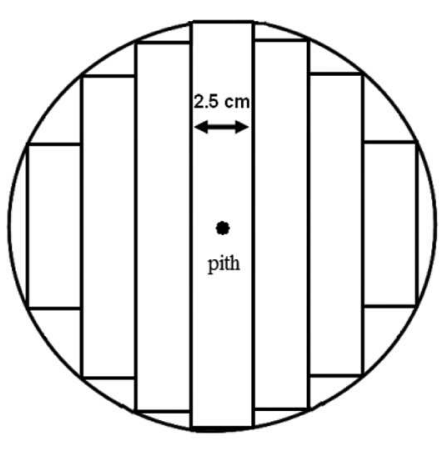

(a)

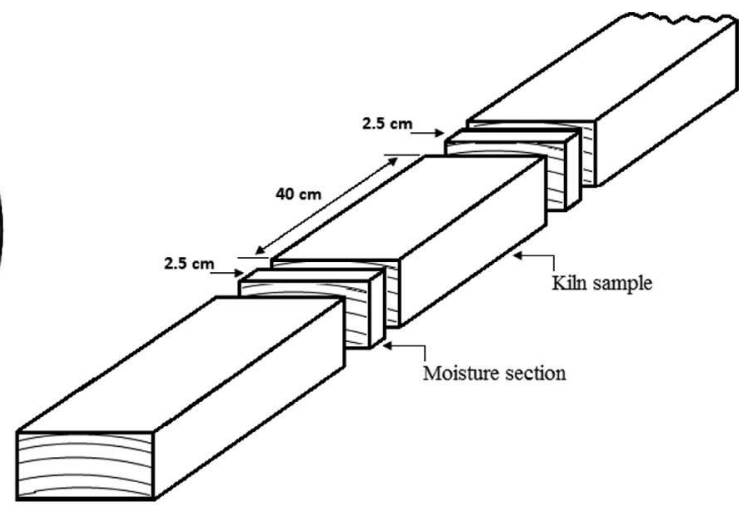

(b)

Figure 1. (a) Sawing pattern used on each log and (b) sample obtained for determination of moisture content in the board. 


\section{Sawing pattern}

The logs were sawn using a pattern commonly used by the Costa Rican furniture industry to produce $25-\mathrm{mm}$ thick boards. This sawing pattern is detailed in Moya and $\mathrm{Muñoz}^{[23]}$ and it produces boards with different grain patterns (flat sawn, quarter sawn, rift sawn, and double-rift sawn). All boards were edged (Fig. 1a).

\section{Drying and moisture content control}

Drying was conducted using an electrically heated 2$\mathrm{m}^{3}$-capacity NARDI kiln dryer (Pilot model, Nardi Company, Italy). The drying schedules applied came from different sources (Table 2) and all species were dried separately. These schedules are commonly employed on wood from natural forests. All schedules included heating, drying, equalization, conditioning, and cooling. During the heating stage, optimal temperature conditions were achieved in a 4-h period and then maintained over a 2-h period, after which the drying stage began. The drying stage was made up of 8-10 steps until the target final moisture content $\left(\mathrm{MC}_{f}\right)$ was attained: $12 \%$ moisture content (MC) for C. alliodora, E. cyclocarpum, $H$. alchorneoides, and $V$. ferruginea and $10 \% \mathrm{MC}$ for $D$. panamensis and S. saman. The equalization stage lasted $2 \mathrm{~h}$ from the moment all of the wood samples reached the target $\mathrm{MC}_{f}$. A 2-h conditioning stage was programmed for the relief of the stresses that occur during the drying. Finally, the cooling stage was programmed at $25^{\circ} \mathrm{C}$ over a 6 -h period. The equilibrium moisture content (EMC) is controlled inside the chamber by a commercial cellulose sensor with an error of $1 \%$. It important to clarify that different species were not compared because different drying schedules were used for the various species, making it impossible to compare drying rates among those species, because drying rates are obviously dependent of the schedule used.

For MC control, six representative samples were selected. Kiln samples $400 \mathrm{~mm}$ long were obtained from boards in the middle of the lumber packages and these were representative of the load. ${ }^{[24]}$ The samples were placed at different heights in the package inside the drying chamber. Before beginning drying, the $\mathrm{MC}_{i}$ was determined. It was measured from the $2.5 \mathrm{~cm}$ transversal section obtained from each board (Fig. 1b). MC was determined using ASTM standard D-4442-92 and it was calculated in relation to green weight. ${ }^{[25]}$ The MC value obtained was then attributed to the six representative samples. Kiln samples were weighed daily and their drying rate was established. Then the change in the schedule (step) was applied based on the MC of the six representative samples.

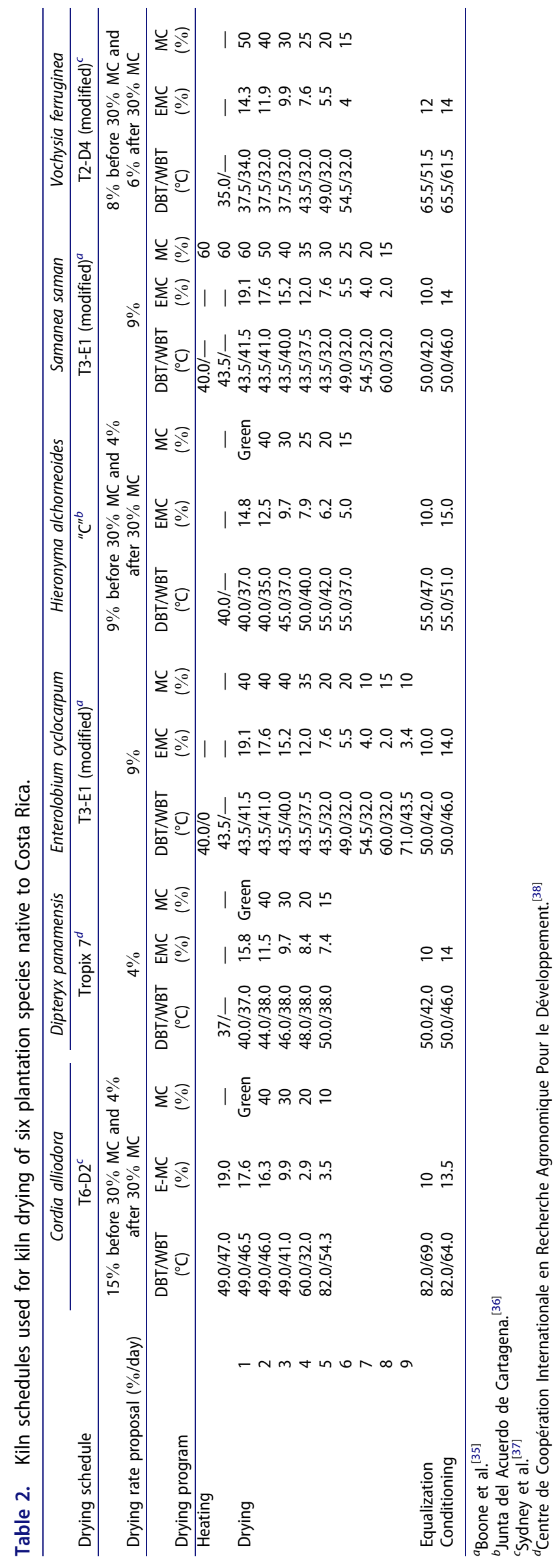




\section{Data analysis}

The average, coefficient of variation, and maximum and minimum values were all determined for $\mathrm{MC}_{i}$ and $\mathrm{MC}_{f}$. The average drying rate was calculated with the values from $\mathrm{MC}_{i}, \mathrm{MC}_{f}$ and drying time (Eq. (1)) and the experimental error is $3 \%$.

$$
\begin{aligned}
& \begin{array}{l}
\text { Average drying rate (\%/days) } \\
=\frac{(\text { initial MC(\%) }- \text { final MC(\%)) }}{\text { drying time (days) }} .
\end{array}
\end{aligned}
$$

Next, the variation in $\mathrm{MC}$ with time was determined. For this purpose, data from the six control samples were employed. The variation in MC with time was modeled by means of an exponential or polynomial model (Eqs. (2) and (3)). The model showing the highest coefficient of determination $\left(R^{2}\right)$ was selected. For C. alliodora, D. panamensis, $H$. alchorneoides, and $V$. ferruginea the selected model was exponential (Eq. (2)) and for E. cyclocarpum and S. saman the selected model was polynomial (Eq. (3)).

$$
\begin{gathered}
\mathrm{MC}=a * e^{-b * t} \\
\mathrm{MC}=a t^{2}+b t+c,
\end{gathered}
$$

where MC is the moisture content $(\%) ; t$ is the drying time (hours); and $a, b$, and $c$ are coefficients of the model. Beause the drying process was done separately, each model of Eqs. (2) and (3) was calculated for each species.

Finally, the drying rate was determined for each drying measurement day, with the purpose of establishing the behavior with time of this parameter. For this, Eq. (1) was used again, but the initial and final MC values correspond to the MC obtained for each day during the whole drying process. This drying rate value was then correlated to the MC measured during the various days and a linear regression model was adjusted between these two variables. The data for E. cyclocarpum and S. saman presented two tendencies; therefore, the data were separated and the regression model was adjusted for each group of data. The drying rate and drying time were also correlated. As observed in this analysis, two to three tendencies or stages appeared during the drying time and therefore a linear regression model was again adjusted for each stage. Once the models were adjusted, the inflexion points or the change in tendency between the variation in drying rate and time for each species were determined. Likewise, by means of Eq. (1), the average drying rate observed in the various drying stages established by the inflexion points was determined; the difference was that the initial and final $\mathrm{MC}$ values correspond to the MC shown by the wood at the beginning and the end of the stages found.

\section{Results}

\section{Moisture contents and drying time}

For C. alliodora, E. cyclocarpum, H. alchorneoides, and $V$. ferruginea the $\mathrm{MC}_{i}$ was over $100 \%$ (water content is greater than the oven-dried weight of wood), whereas for D. panamensis and S. saman it was less than $100 \%$ (Table 3). Almost all of the species showed a coefficient of variation $(\mathrm{CV})$ greater than $20 \%$ in the $\mathrm{MC}_{i}$ values, with the exception of E. cyclocarpum $(9.6 \%)$ and $S$. saman $(13.6 \%)$. Concerning the $\mathrm{MC}_{f}$ it was found that, among the species with a target MC of $10 \%$, the value was $11.9 \%$ for D. panamensis and $10.9 \%$ for S. saman. For the rest of the species with a target MC of $12 \%$, the $\mathrm{MC}_{f}$ varied from 9.7 to $12.4 \%$ (Table 3). As before, the $\mathrm{CV}$ of the $\mathrm{MC}_{f}$ was high and showed a variation greater than $20 \%$ for D. panamensis, E. cyclocarpum, S. saman, and $V$. ferruginea, whereas for $C$. alliodora and $H$. alchorneoides it was less than $20 \%$.

Regarding the drying time, E. cyclocarpum was the species with the longest drying time $(447 \mathrm{~h})$, whereas $C$. alliodora was the species with the shortest drying time $(168 \mathrm{~h})$. The remaining species (D. panamensis, H. alchorneoides, S. saman, and $V$. ferruginea) showed drying times greater than $200 \mathrm{~h}$ but less than $400 \mathrm{~h}$ (Table 3). Concerning the average drying rate, $C$. alliodora was the species with the highest drying rate and $D$. panamensis was the species with the lowest drying rate (Table 3 ). V. ferruginea showed a high drying rate as well, greater than $12 \% / \mathrm{h}$, whereas the rest of the species (E. cyclocarpum, $H$. alchorneoides, and S. saman) showed values below $10 \% / \mathrm{h}$.

Table 3. Drying parameters of 25-mm-thick boards from six plantation species native to Costa Rica. ${ }^{a}$

\begin{tabular}{lccccc}
\hline Species & Specific gravity & Initial moisture content (\%) & Final moisture content (\%) & Drying time (h) & Drying rate (\%/day) \\
\hline Cordia alliodora & 0.39 & $165.8(32.1)[107.9-250.8]$ & $11.5(9.7)[9.6-12.7]$ & 168 & 21.6 \\
Dipteryx panamensis & 0.62 & $53.1(21.9)[41.1-74.7]$ & $11.9(26.7)[7.1-16.1]$ & 264 & 3.8 \\
Enterolobium cyclocarpum & 0.35 & $167.4(9.6)[147.8-185.5]$ & $9.7(34.3)[5.7-14.2]$ & 447 & 8.4 \\
Hieronyma alchorneoides & 0.50 & $111.6(23.6)[82.3-152.7]$ & $9.5(7.7)[8.6-10.4]$ & 254 & 9.6 \\
Samanea saman & 0.49 & $96.5(13.6)[80.8-119.7]$ & $10.9(22.6)[6.3-12.7]$ & 238 & 8.6 \\
Vochysia ferruginea & 0.37 & $183.5(24.4)[118.9-238.3]$ & $12.4(26.9)[8.9-17.4]$ & 319 & 12.9 \\
\hline
\end{tabular}

${ }^{a}$ Values in parentheses represent coefficients of variation, and values in brackets represent the minimum and maximum values. 

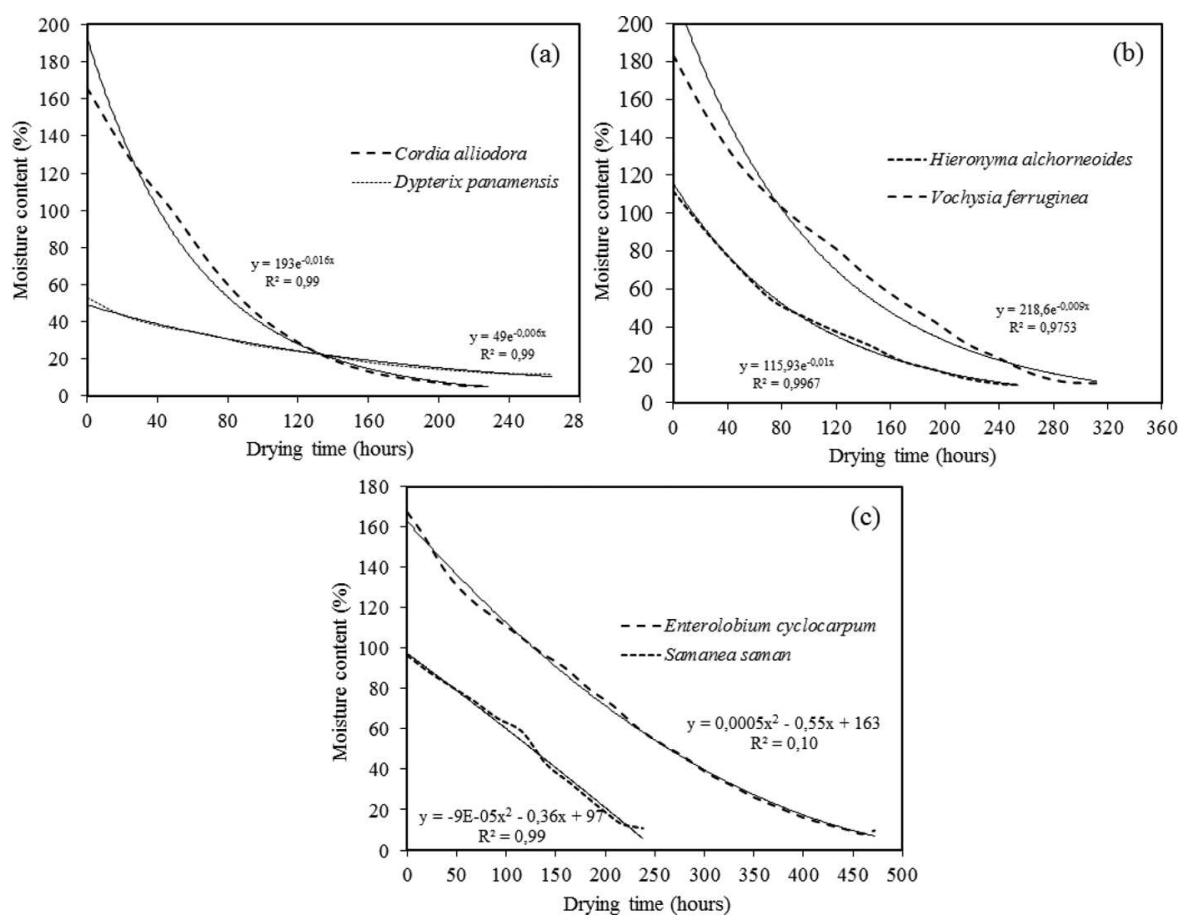

Figure 2. Variation in moisture content during drying: (a), (b) exponential model and (c) polynomial model.

Figure 2 presents the variation with time of the MC for the lumber. The MC was mathematically modeled based on the drying time by means of an exponential equation $\left(\mathrm{MC}=a^{*} e^{-b^{*} t}\right.$, where $t$ is the drying time and $a$ and $b$ are constants that were calculated for each species) for $C$. alliodora, D. panamensis, $H$. alchorneoides, and $V$. ferruginea (Figs. 2a, 2b, 2d, and 2f), whereas for E. cyclocarpum and S. saman (Figs. $2 \mathrm{c}$ and $2 \mathrm{e}$ ) the mathematical model employed was a quadratic polynomial $\left(\mathrm{MC}=a * t^{2}+b * t+c\right.$, where $t$ is the drying time and $a, b$, and $c$ are constants). Almost all of the species (C. alliodora, E. cyclocarpum, $H$. alchorneoides, and S. saman) showed an $R^{2}$ greater than $90 \%$, whereas $D$. panamensis and $V$. ferruginea showed an $R^{2}$ of 85 and $88 \%$ respectively.

\section{Drying rate vs. moisture content}

Figure 3 shows the relation between the drying rate and MC. For C. alliodora, D. panamensis, H. alchorneoides, and $V$. ferruginea the relation was linear (drying rate $=a * t+c$, where $t$ is the drying time and $a$ is a constant), showing a decrease in the drying rate as the MC decreases. In $H$. alchorneoides and $V$. ferruginea the $R^{2}$ is greater than $70 \%$ (Figs. $3 \mathrm{~d}$ and $3 \mathrm{f}$ ), whereas a greater dispersion is observed in C. alliodora and $D$. panamensis, where $R^{2}$ is 62 and $59 \%$, respectively (Figs. $3 \mathrm{a}$ and $3 \mathrm{~b}$ ). E. cyclocarpum and S. saman also showed a linear relation between the drying rate and MC; however, two types of tendencies were observed. For
E. cyclocarpum, with MC less than $80 \%\left(R^{2}=63 \%\right)$, the value of the constant drying rate in relation to the MC (RCMC, \%/day-MC) is lower than that obtained when the MC exceeds $80 \%$, with an $R^{2}$ of $69 \%$ (Fig. 3c). In $S$. saman, when the MC is lower than $40 \%$, the value of RCMC ( $\%$ /day-MC) is greater $\left(R^{2}=65 \%\right)$ than that observed for MCs above $40 \%\left(R^{2}=32 \%\right.$; Fig. $\left.3 \mathrm{e}\right)$.

An important aspect to highlight in C. alliodora, E. cyclocarpum, $H$. alchorneoides, and $V$. ferruginea is that the tendency that appeared in the drying rate when the MCs are greater than $20 \%$ does not appear when the $\mathrm{MC}$ is lower than $20 \%$, which corresponds to drying rates under $5 \% /$ day. In addition, low dispersion of the drying rate values is observed when the MC decreases below 20\% (Figs. 3a, 3c, 3d, and 3f).

\section{Drying rate vs. drying time}

A decrease in drying rate with drying time was observed (Fig. 4). However, two different stages were determined in C. alliodora, E. cyclocarpum, and S. saman (Figs. 4a, $4 \mathrm{c}$, and $4 \mathrm{e}$ ), whereas three stages were determined for D. panamensis, $H$. alchorneoides, and $V$. ferruginea (Figs. 4b, 4d, and 4f). In C. alliodora and E. cyclocarpum, for up to 144 and $159 \mathrm{~h}$, respectively (Figs. $4 \mathrm{a}$ and $4 \mathrm{c}$ ), the constant drying rate in relation to the drying time (RCDT) (\%/day-h) is greater than the RCDT value observed for subsequent drying times. Nevertheless, for this first stage (from the beginning until 144 and $159 \mathrm{~h}$ for C. alliodora and E. cyclocarpum, respectively) the 

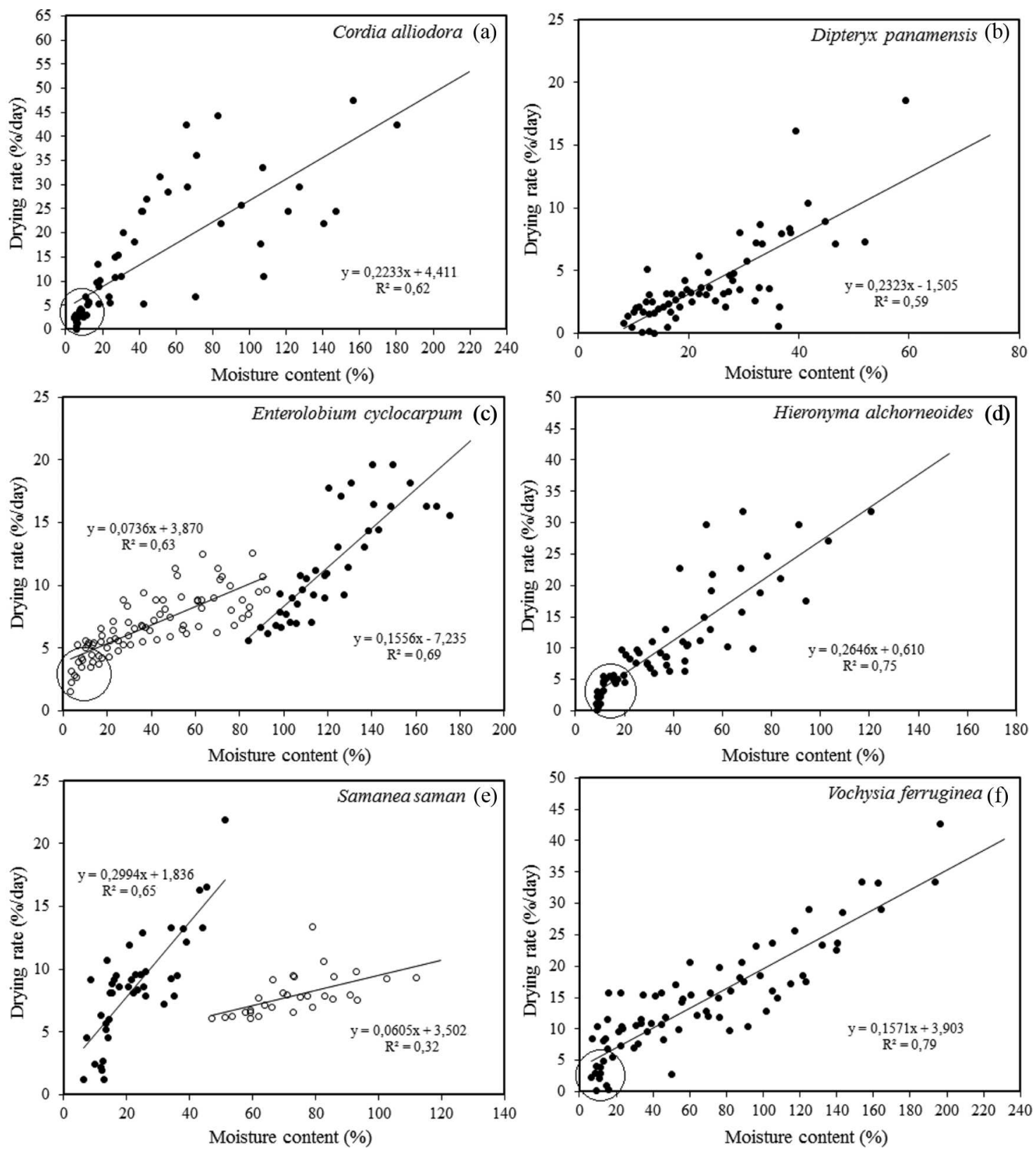

Figure 3. Variation in drying rate with moisture content for six plantation species native to Costa Rica.

$R^{2}$ is lower than that obtained for the stage subsequent to the aforementioned times (Figs. 4a and 4c). Contrariwise, in $S$. saman, for drying times less than $116 \mathrm{~h}$, the RCDT value (\%/day-h) was less than that obtained for drying times greater than $116 \mathrm{~h}$, whereas the behavior of the $R^{2}$ was the same as with the two previous species (Fig. 4e).

With respect to the species in which three stages appeared (D. panamensis, $H$. alchorneoides, and $V$. ferruginea), the following were observed: (1) a first stage takes place from the beginning of drying until 68, 73, and $96 \mathrm{~h}$ for $D$. panamensis, $H$. alchorneoides, and $V$. ferruginea, respectively, in which higher RCDT are obtained, with $R^{2}$ of 45,7 , and $56 \%$, respectively; (2) in the stage between the previous times and 163 , 168 , and $216 \mathrm{~h}$, respectively, more stable or constant RCDT was observed, with $R^{2}$ of 19,9 , and $4 \%$, respectively; (3) with drying times greater than 163,168 , and $216 \mathrm{~h}$, respectively, a behavior similar to that of the first stage is observed, where the drying rate decreases as the drying time increases. However, the decrease in RCDT for the third stage is lower (Figs. $4 \mathrm{~b}, 4 \mathrm{~d}$, and $4 \mathrm{f}$ ).

The results presented previously make it possible to establish points of inflexion in the variation in drying rate in relation to time. In C. alliodora, E. cyclocarpum, 

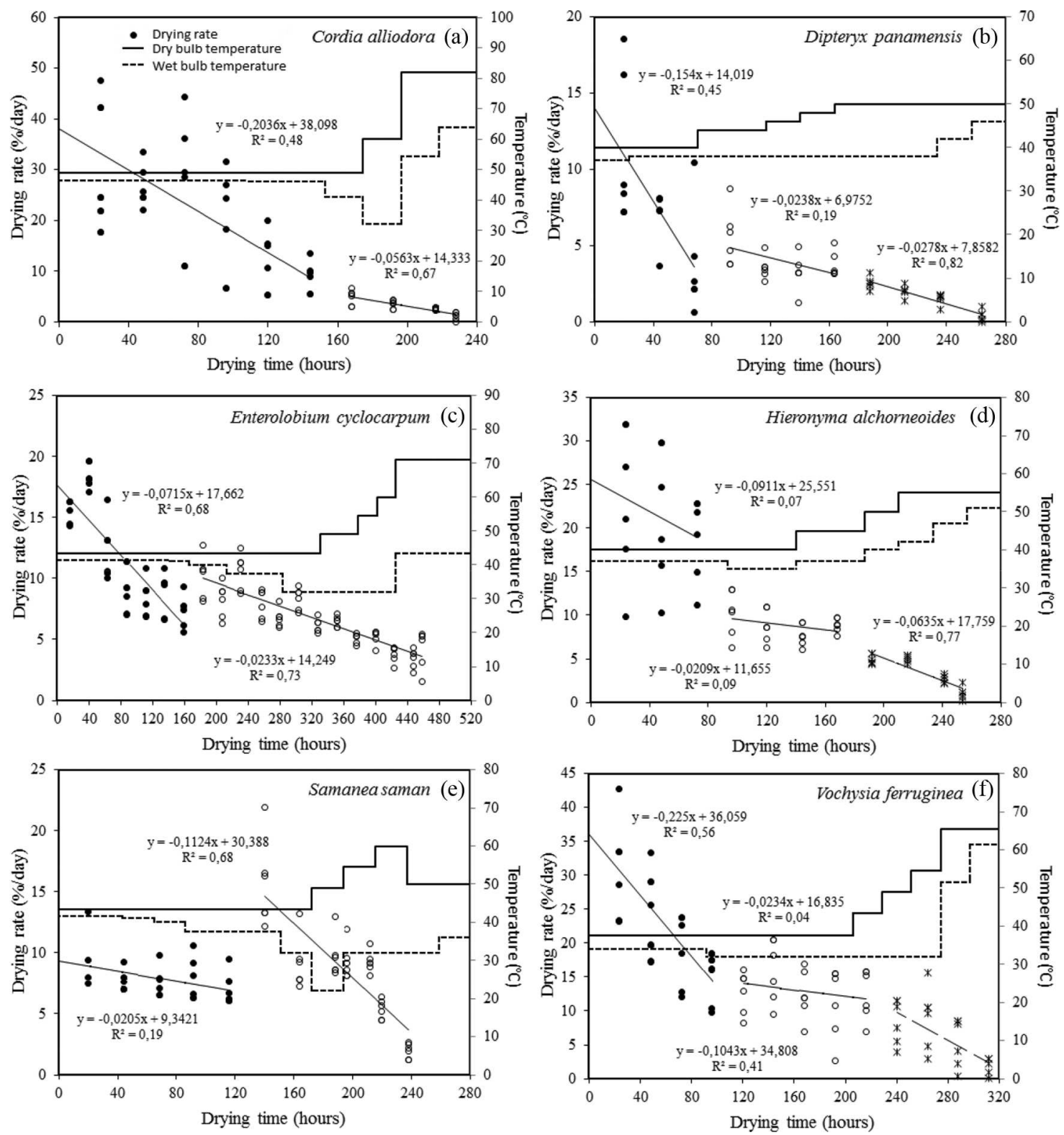

Figure 4. Variation in drying rate in relation to drying time for six plantation species native to Costa Rica.

and S. saman, for which two stages during drying were defined, the point of inflexion occurs at 144, 159 , and $116 \mathrm{~h}$, respectively. For D. panamensis, $H$. alchorneoides, and $V$. ferruginea, for which three stages of drying are defined, the first inflexion occurs at 68,73 , and $96 \mathrm{~h}$ after drying began, whereas the second point of inflexion takes place at 163,168 , and $216 \mathrm{~h}$, respectively. The MC for each species at the points of inflexion and the drying rate for each stage of drying are shown in Table 4 .

Table 4. Drying time, moisture content, and drying rate at the inflexion point of the gradient of variation in drying rate in relation to drying time for six plantation species native to Costa Rica.

\begin{tabular}{|c|c|c|c|c|c|c|c|}
\hline \multirow[b]{2}{*}{ Species } & \multicolumn{2}{|r|}{ Point 1} & \multicolumn{2}{|r|}{ Point 2} & \multicolumn{3}{|c|}{ Drying rate $(\% /$ day $)$} \\
\hline & Time (h) & Moisture content $(\%)$ & Time (h) & Moisture content $(\%)$ & Stage 1 & Stage 2 & Stage 3 \\
\hline Cordia alliodora & 144 & 18.0 & & & 24.5 & 3.6 & \\
\hline Dipteryx panamensis & 68 & 33.5 & 163 & 17.8 & 7.0 & 4.1 & 1.4 \\
\hline Enterolobium cyclocarpum & 159 & 90.3 & & & 11.6 & 6.6 & \\
\hline Hieronyma alchorneoides & 73 & 54.1 & 168 & 22.0 & 18.9 & 8.1 & 3.5 \\
\hline Samanea saman & 116 & 58.6 & & & 7.8 & 9.4 & \\
\hline Vochysia ferruginea & 96 & 93.6 & 216 & 31.1 & 22.5 & 12.5 & 5.2 \\
\hline
\end{tabular}




\section{Analysis of results}

\section{Moisture contents and drying times}

The $\mathrm{MC}_{i}$ obtained in this study varied from 53.1 to $183.5 \%$, similar to values obtained for other species from forest plantations in Costa Rica. ${ }^{[14,17,26,27]}$ However, in those specific studies, the studied plants showed coefficients of variation lower than $18 \%$, in contrast to the coefficients of variation obtained in this study, most of which were greater than $20 \%$ (Table 3 ).

The high value found for the coefficient of variation of the studied species can be explained by the fact that the lumber samples were extracted from different parts of the tree. It has been noted that the variations in $\mathrm{MC}_{i}$ are determined by characteristics inherent to each species (such as the specific gravity and the sapwoodheartwood relation) and to the specific tree section (such as the distance from the board to the pith and the height of the tree). ${ }^{[23,26-28]}$

The target MC for the species was $10 \%$ (D. panamensis and S. saman) and $12 \%$ (C. alliodora, E. cyclocarpum, $H$. alchorneoides, and V. ferruginea); however, considerable variations were observed (Table 3), despite the equalization and conditioning stages that were applied at the end of drying. These variations in $\mathrm{MC}_{f}$ of the species and in the target $\mathrm{MC}$ can be attributed to inadequate equalization and conditioning stages with time. On the other hand, these differences can also be attributed to differences between the moisture measured with electrical humidity gauges and the moisture estimated by employing the humidity control samples. In this study, the control of drying was done by employing humidity control samples. For the equalization and conditioning stages, however, because the time available was limited, it was necessary to use the electrical humidity gauges of the dryer. These electrical humidity gauges used in kiln dryers can be affected by factors in addition to the $\mathrm{MC}-$ extractives, for example ${ }^{[29]}$ - that appear in high values in tropical species. ${ }^{[30]}$ Furthermore, electrical humidity gauges are not precise for moisture contents over the fiber saturation point and, below this point, they require temperature adjustments, which renders them inappropriate for full control of the drying. ${ }^{[31]}$ A practical effect of the high variation in $\mathrm{MC}_{f}$ is that lumber with this high $\mathrm{MC}_{f}$ variation could be acceptable for use in construction but certainly not for value-added products.

Concerning the drying time, it was possible to observe differences among the species (Table 3). Langrish $^{[32]}$ noted that species with high specific gravity and high percentages of heartwood require longer drying times compared to species with low specific gravity and low percentages of heartwood; nevertheless, the results from the present study differ from those. It was not possible to establish a relation with drying time between the specific gravity and the heartwood percentage, with the exception of E. cyclocarpum, which is the species with the second to highest heartwood percentage and the one with the longest drying time, although it possesses the lowest specific gravity (Table 3 ). This means that the heartwood of E. cyclocarpum does influence the drying time.

The average drying rate variation found (from 3.84 to $21.6 \%$ /day, Table 3) for the six species had lower values than those obtained for the 10 forest plantation species in Costa Rica. ${ }^{[14]}$ The variation obtained in this parameter for the studied species as well as other species is attributed to the characteristics inherent to the wood, ${ }^{[6,7]}$ the characteristics of the drying chamber, ${ }^{[8]}$ and the conditions (temperature, relative humidity, and wind speed) used during drying. ${ }^{[6]}$ It is important to clarify that although the drying rates were compared between species, this situation could vary because the drying rates are obviously different for each drying schedule used.

\section{Drying rate vs. moisture content}

The coefficients of correlation $\left(R^{2}\right)$ over $50 \%$ in the linear models between the drying rate and the $\mathrm{MC}$ for the six species (Fig. 3) indicate that the MC of the lumber can be used as a predictor of the variation in drying rate of these species. These low coefficients can be explained by the large variation in moisture content of kiln samples. For five of the species, with the exception of E. cyclocarpum, the coefficient of variation varied from 13.6 to $32.1 \%$ (Table 3 ), thus showing high moisture variation, and therefore differences in drying rate were found, decreasing the $R^{2}$ of the mathematical model. However, the tendencies found for C. alliodora, $D$. panamensis, $H$. alchorneoides, and $V$. ferruginea differed from those found for E. cyclocarpum and S. saman (Fig. 3). In the first four species, the drying rate decreased steadily as the MC decreased; that is, the RCMC was the same during the whole distribution of the MC.

Regarding E. cyclocarpum and S. saman, two linear tendencies are observed; that is, two RCMC appear (Figs. $3 \mathrm{c}$ and $3 \mathrm{e}$ ). These two tendencies can be explained by the high percentage of heartwood present in these species (33.14 and $52.51 \%$, respectively, when measured as a $\log$ ) but, once the lumber is sawn, this percentage increases due to the removal of the ribs, which contain a high amount of sapwood, resulting in boards with high percentages of heartwood, as can be seen in Figs. $5 \mathrm{c}$ and $5 \mathrm{e}$. This differs from the four previous 

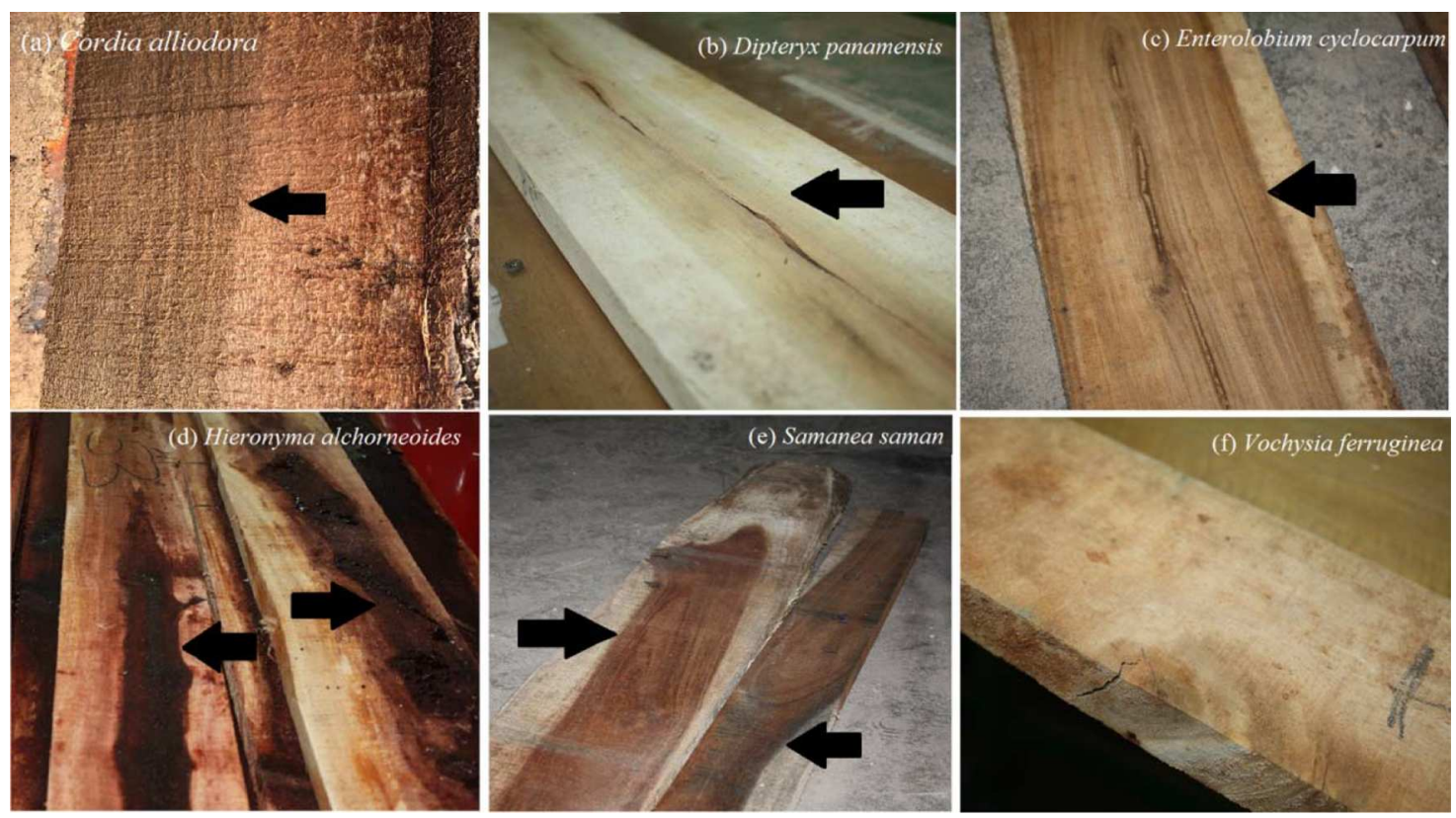

Figure 5. Heartwood presence (arrows) in dried lumber from six plantation species native to Costa Rica.

species, which show little to no heartwood in the sawn lumber (Figs. 5a, 5b, 5d, and 5f). Unlike heartwood, sapwood is permeable to liquids due to its lack of extractives in the intercellular spaces, thus allowing better and faster fluid movement than in the heartwood. ${ }^{[33]}$ The latter is less permeable because several chemical substances (extractives) tend to deposit in its cells, making fluid conduction through heartwood very slow. ${ }^{[6,32,34]}$ Consequently, the drying rate in E. cyclocarpum and $S$. saman could be affected by the transition between the sapwood and the heartwood, because water movement in heartwood is slower, causing changes in the drying rate tendency of these species (Figs. $3 c$ and $3 e$ ).

\section{Drying rate vs. drying time}

Regarding the drying rate vs. drying time relation, two tendencies were observed for C. alliodora, E. cyclocarpum, and S. saman and three for D. panamensis, $H$. alchorneoides, and V. ferruginea (Fig. 4). This can be explained again by the limited water movement in the lumber, which is influenced by $\mathrm{MC}_{i}$, the anatomical characteristics, and the heartwood-sapwood proportion of each species. ${ }^{[33]}$ In E. cyclocarpum and S. saman it is possible that the points of inflexion at 93.63 and $54.11 \%$ MC (Figs. 4c and 4e, Table 3), respectively, are a result of the differentiation between sapwood and heartwood (Fig. 5). For C. alliodora, the point of inflexion appears at an $\mathrm{MC}$ lower than $18 \%$, which could be related to the water movement, because this species showed a lower heartwood percentage (Fig. 4a, Table 4).
In D. panamensis, H. alchorneoides, and V. ferruginea, in which three stages were defined in the drying rate in relation to time (Figs. $4 \mathrm{~b}, 4 \mathrm{~d}$, and $4 \mathrm{f}$ ), the first point of inflexion occurs at an MC greater than $50 \%$ (33.50, 54.11 , and $93.63 \%$, respectively), which could be related to the variations in water movement in the sapwood lumber. The second point of inflexion occurs at MC lower than $30 \%(17.81,22.03$, and $31.14 \%$, respectively), which again indicates the influence of bound water movement on the drying rate (Figs. $4 \mathrm{~b}, 4 \mathrm{~d}$, and $4 \mathrm{f})$.

Modeling of the variation in drying rate based on time (Fig. 4) allows determination of the various stages that appear during drying as well as the points of inflexion in time for the drying rate. These points of inflexion result from changes in the dry bulb and wet bulb temperatures (DBT and WBT, respectively), which cause various bulb depressions during drying of lumber (Fig. 4). The first inflexion, in the majority of cases, corresponds to the first change in DBT and WBT or the first step of drying. The times of the first inflexion (indicated in Table 4 for the six species) correspond to a decrease in WBT for all of the species (Fig. 4), with the exception of $C$. alliodora, in which an increase in DBT occurs instead (Fig. 4).

For the species that showed one inflexion only, C. alliodora, E. cyclocarpum, and S. saman, this seems to indicate that the drying rate can be maintained at an average of $24.5,11.64$, and $7.83 \%$ /day, respectively, until the $\mathrm{MC}$ reaches the value indicated in the first step of the programs shown in Table 2, which means 45, 40, 
and $60 \%$, respectively. After this MC has been reached, the changes in DBT and WBT conditions will begin to produce a constant decrease in the drying rate with time (Figs. 4a, 4c, and 4e). To control the drying process, however, the average for that decrease could be employed: $3.6 \%$ /day for C. alliodora, $6.58 \%$ /day for E. cyclocarpum, and $9.40 \%$ /day for S. saman.

For D. panamensis, H. alchorneoides, and V. ferruginea, which showed two inflexions during drying, the drying rate can be maintained at the average indicated in Table 4 until the MC indicated in the first stage of the drying program (Table 2) is achieved, specifically, $40 \%$ for the first two species and $50 \%$ for $V$. ferruginea. In contrast to the previous species, these three species present a time period at which the drying rate is slightly constant before the drying rate starts to decrease again with time (Figs. $4 \mathrm{~b}, 4 \mathrm{~d}$, and $4 \mathrm{f}$ ). The average drying rates recommended for these species are those indicated in stage 2 of Table 4 . This intermediate phase in the drying rate is not related to any strong change in DBT or WBT conditions when drying (Figs. $4 \mathrm{~b}, 4 \mathrm{~d}$, and $4 \mathrm{f}$ ); therefore, the change is probably more influenced by the movement of released water inside the lumber, because this period occurs before the fiber saturation point. Finally, in the third stage, the drying rate again decreases with time and it is advisable to maintain the drying rate at $1.44 \%$ /day in D. panamensis, $3.51 \%$ /day in $H$. alchorneoides, and $5.24 \%$ /day in V. ferruginea (Table 4).

An important aspect to highlight in relation to the various drying rates proposed for each species (Table 2 ) is that these are very different from the real rates found for the various species (Table 4). One factor that contributes to this is the high $\mathrm{MC}_{i}$ characteristic of tropical species (greater than 100\%) such as C. alliodora, E. cyclocarpum, $H$. alchorneoides, and $V$. ferruginea, which make it impossible to maintain those rates during the whole drying process. This suggests the need to perform more studies involving the relation between the drying rate and drying time for tropical plantation species with high $\mathrm{MC}_{i}$.

\section{Conclusions}

The $\mathrm{MC}_{i}$ for the six species varied from 53.1 to $183.5 \%$. The $\mathrm{MC}_{f}$ varied $2 \%$ in relation to the average target defined for the species. The majority of species showed a coefficient of variation greater than $20 \%$ in the $\mathrm{MC}_{i}$ and $\mathrm{MC}_{f}$ values.

The MC of the lumber is a good predictor of the variation of the drying rate and it can be modeled by the relation drying rate $=a * t+b$ (where $t$ is the drying time and $a$ and $b$ are constants), with $R^{2}$ greater than 50\%. C. alliodora, D. panamensis, H. alchorneoides, and $V$. ferruginea showed a unique tendency, whereas E. cyclocarpum and S. saman showed two tendencies, in which the point of change was at 80 and $40 \% \mathrm{MC}$, respectively. Moreover, it was observed that for $\mathrm{MC}$ lower than $20 \%$ (C. alliodora, E. cyclocarpum, $H$. alchorneoides, and $V$. ferruginea) the previously described model is hardly applicable.

Modeling of the variation in drying rate in relation to time made it possible to establish different stages that appear in the drying of each species, as well as establish the points of inflexion in time where a change in the drying rate occurs. Two types of tendencies are shown in the drying rate vs. time relation in C. alliodora, E. cyclocarpum, and S. saman, whereas three tendencies appeared in D. panamensis, $H$. alchorneoides, and V. ferruginea. C. alliodora, E. cyclocarpum, and S. saman showed only one inflexion in the drying rate, whereas $D$. panamensis, $H$. alchorneoides, and $V$. ferruginea showed two inflexions.

\section{References}

[1] Laguarda, M.F.; Espinoza, O.; Erickson, R. Green kerfing treatment for improving softwood lumber drying: A review. Drying Technology 2014, 32(5), 606-613.

[2] Gu, H.; Young, T.M.; Moschler, W.W.; Bond, B.H. Potential sources of variation that influence the final moisture content of kiln-dried hardwood lumber. Forest Products Journal 2004, 54(11), 65-70.

[3] Jankowsky, I.P.; Goncalves, M. Review of wood drying research in Brazil: 1984-2004. Drying Technology 2006, 24, 447-455.

[4] Park, J.H.; Park, Y.; Han, Y.; Choi, J.W.; Choi, I.G. Lee, J.J.; Yeo, H. Effect of outer surface sealing treatment on the reduction of surface check occurrence during the drying of center-bored round timber. Drying Technology 2014, 32, 236-243.

[5] Murphy, J.T.; Schindler, S. Globalizing development in Bolivia? Alternative networks and value-capture challenges in the wood products industry. Journal of Economic Geography 2011, 11(1), 61-85.

[6] Denig, J.; Wengert, E.M.; Simpson, W.T. Drying Hardwood Lumber. U.S. Department of Agriculture, Forest Products Laboratory: Madison, WI, 2000.

[7] Klitzke, R.J.; Batista, D.C. Tests of drying rate and scoring of defects for the prediction of conventional kiln drying quality of Eucalyptus wood. Scientia Forestalis 2010, 38(85), 97-105.

[8] Espinoza, O.; Bond, B.H.; Araman, P. A survey of Bolivian lumber drying operations. Forest Products Journal 2007, 57(6), 88-92.

[9] Harris, R.A.; Schroeder, J.G.; Addis, S.C. Steaming of red oak prior to kiln-drying: Effects on moisture movement. Forest Products Journal 1989, 39, 11-12.

[10] Dashti, H.; Tarmian, A.; Faezipour, M.; Shahverdi, M. Effect of microwave radiation and pre-steaming treatments on the conventional drying characteristics of fir wood (Abies alba L.). Lignocellulose 2012, 1(3), 166-173. 
[11] Shahverdi, M.; Dashti, H.; Hossein, M.A. Establishing a kiln drying schedule for poplar (Populus alba L.) lumber of $7 \mathrm{~cm}$ thickness. BioResources 2012, 7(1), 26-37.

[12] Mendes, A.S.; Simpsom, W.T.; Verril, S.P. Laboratory test for grouping tropical species for kiln drying. Wood Science and Technology 1995, 29, 353-362.

[13] Ananías, R.A.; Sepúlveda-Villarroel, V.; Pérez-Peña, N.; Leandro-Zuñiga, L.; Salvo-Sepúlveda, L.; Salinas-Lira, C.; Elustondo, D.M. Collapse of Eucalyptus nitens wood after drying depending on the radial location within the stem. Drying Technology, 2014, 32(14), 1699-1705.

[14] Moya, R.; Ureña, E.; Salas, C.; Muñoz, F.; Espinosa, O. Kiln drying behavior of lumber from ten fast-growth plantation species in Costa Rica. Wood Material Science and Engineering 2013, 8(1), 37-45.

[15] Petit, B.; Montagnini, F. Growth equations and rotation ages of ten native tree species in mixed and pure plantations in the humid neotropics. Forests Ecology and Management 2004, 199, 243-257.

[16] Nichols, J.D; Vanclay, J.K. Domestication of native tree species for timber plantations: Key insights for tropical island nations. International Forestry Review 2012, 14(4), 402-413.

[17] Moya, R.; Muñoz, F. Physical and mechanical properties of eight species growing in fast growth plantations in Costa Rica. Journal of Tropical Forest Science 2010, 22 (3), 317-328.

[18] Moya, R.; Tenorio, C. Fuelwood characteristics and its relation with extractives and chemical properties of ten fast-growth species in Costa Rica. Biomass and Bioenergy 2013, 56, 14-21.

[19] Muñoz, F.; Moya, R. Moisture content variability in kilndried Gmelina arborea wood: Effect of radial position and anatomical features. Journal of Wood Science 2008, $54,318-322$.

[20] Moya, R.; Leandro, L.; Murillo, O. Wood characteristics of Terminalia amazonia, Vochysia guatemalensis and Hieronyma alchorneoides planted in Costa Rica. Bosque 2009, 30(2), 78-87.

[21] Butterfield, R.; Crook, R.P.; Adams, R.; Morris, R. Radial variation in wood specific gravity, fiber length and vessel area for two Central American hardwoods; Hieronyma alchorneoides and Vochysia guatemalensis: Natural and plantation-grown trees. IAWA Journal 1993, 17, 5-14.

[22] González, E.J.; Fisher, R.F. Growth of native forest species planted on abandoned pasture land in Costa Rica. Forests Ecology and Management 1994, 70, 159-167.

[23] Moya, R.; Muñoz, F. Wet pockets in kiln-dried Gmelina arborea lumber. Journal of Tropical Forest Science 2008, 22(3), 317-328.

[24] Simpson, W. Properties of wood related to drying. In Dry Kiln Operator's Manual Handbook; Simpson, W. Ed.; USDA Forest Service, Forest Products Laboratory: Madison, WI, 1991; I1-I50.
[25] American Society for Testing and Materials. Standard Test Methods for Direct Moisture Content Measurements of Wood and Wood-Base Materials, ASTMD-4442-92: American Society for Testing and Materials: West Conshohocken, PA, 2003.

[26] Moya, R.; Aguilar, D.; Tenorio, C.; Bond, B. Variation of moisture content in kiln dried plantation grown lumber of Vochysia guatemalensis. Wood Fiber and Science 2011, 43(2), 121-129.

[27] Tenorio, C.; Moya, R. Kiln dry of Acacia mangium (Willd): Moisture content, wood color and drying defects after and before drying. Drying Technology 2011, 29(15), 1845-1854.

[28] Qumruzzaman, C.; Iftekhar, S.; Mahbubul, A. Effects of age and height variation on physical properties of mangium (Acacia mangium Willd) wood. Australian Forestry 2005, 68, 17-19.

[29] James, W. Electric Moisture Meters for Wood, General Technical Report FPL-GTR-6; U.S. Department of Agriculture, Forest Service, Forest Products Laboratory: Madison, WI, 1988.

[30] Tenorio, C.; Moya, R. Thermogravimetric characteristics, its relation with extractives and chemicalproperties and combustion characteristics of ten fast-growth species in Costa Rica. Thermochimica Acta 2013, 563, 12-21.

[31] Forsén, H.; Tarvainen, V. Accuracy and Functionality of Hand Held Wood Moisture Content Meters. VTT Publication 420; Technical Reseach Centre of Finland; Espoo, 2000.

[32] Langrish, T.A.G. Comparing continuous and cyclic drying schedules for processing hardwood timber: The importance of mechanosorptive strain. Drying Technology 2013, 31(10), 1091-1098.

[33] Skaar, C.; Siau, J.F. Thermal diffusion of bound water in wood. Wood Science and Technology 1981, 15(2), 102-112.

[34] Skaar, C. Water in Wood, 1st ed.; Syracuse University Press: Syracuse, NY, 1972.

[35] Boone, R.S.; Kozlik, C.J.; Bois, P.J.; Wengert, E.M. Dry Kiln Schedules for Commercial Woods-Temperate and Tropical. U.S. Department of Agriculture, Forest Service, Forest Products Laboratory: Madison, WI, 1988.

[36] Junta del Acuerdo de Cartagena. Manual del Grupo Andino para el Secado de Maderas. Proyecto Subregional de Promoción Industrial de la Madera para Construcción: Lima, Perú, 1989.

[37] Sidney, R.; Charles, J.; Kozlik, P.; Bois, J.; Wengert, E. Dry Kiln Schedules for Commercial Woods: Temperate and Tropical, General Technical Report FPL-GTR-57. U.S. Department of Agriculture, Forest Service Forest Products Laboratory: Madison, WI, 1988.

[38] Centre de Coopération Internationale en Recherche Agronomique Pour le Développement. The main technological characteristics of 245 tropical wood species. http://tropix.cirad.fr/FichiersComplementaires/EN/ America/CUMARU.pdf 